\title{
Pulmonary vein stenosis: Case report and literature review
}

\author{
R Amin MD, S Kwon BSc, Y Moayedi BHsc, N Sweezey MD
}

\begin{abstract}
R Amin, S Kwon, Y Moayedi, N Sweezey. Pulmonary vein stenosis: Case report and literature review. Can Respir J 2009;16(6):e77-e80.
\end{abstract}

BACKGROUND: Pulmonary vein stenosis is a rare cause of pulmonary hypertension, with variable onset and presentation. One or more of the four pulmonary veins can be primarily or secondarily affected. A five-month-old girl presented with respiratory distress, lethargy and cyanosis requiring intubation.

METHODS: Echocardiography showed right ventricular dilation, a right ventricular systolic pressure of $97 \mathrm{mmHg}$, decreased ejection fraction and turbulent flow at the left atrium. Cardiac catheterization revealed stenosis of the left-sided pulmonary veins, for which she underwent a Coles procedure.

RESULTS: Postoperatively, there was a transient improvement in the patient's pulmonary hypertension but she subsequently deteriorated. Her prognosis was considered bleak, and a decision was made with the family to withdraw care.

CONCLUSION: Pulmonary vein stenosis is a rare cause of pulmonary hypertension, and is associated with significant morbidity and mortality. Surgical intervention may be of benefit in selected cases. It stands to reason that any treatment will have the best chance of success if completed before the pulmonary hypertension becomes fixed. Early diagnosis depends on a high index of clinical suspicion.

Key Words: Coles procedure; Pulmonary hypertension; Pulmonary vein stenosis

\section{CASE PRESENTATION}

A five-month-old girl presented with a history of cyanosis, lethargy and an oxygen requirement of $1 \mathrm{~L} / \mathrm{min}$ by nasal prongs.

Following birth at 25 weeks gestational age, the patient developed respiratory distress syndrome and, subsequently, bronchopulmonary dysplasia (BPD). She underwent high-frequency oscillation for 11 days, was conventionally ventilated for 73 days and finally, extubated after a $48 \mathrm{~h}$ course of dexamethasone. Her neonatal course was complicated by decreased right vocal cord movement, tracheomalacia, patent ductus arteriosus, and ligation and pulmonary hypertension, for which she received sildenafil. She also had a gastrostomy tube placed because of gastroesophageal reflux and aspiration. She was discharged on $200 \mathrm{~mL} / \mathrm{min}$ of oxygen. On presentation to the emergency room at the Hospital for Sick Children (Toronto, Ontario), her medications comprised sildenafil, hydrochlorothiazide, spironolactone, sodium chloride supplements, budesonide, domperidone, lansoprazole, iron and multivitamin supplements (Trivisol, Mead Johnson, Canada).

The patient was afebrile, with a respiratory rate of 70 breaths/ min, oxygen saturation at $94 \%$ on $60 \%$ oxygen in a head box

\section{La sténose des veines pulmonaires : Un rapport de cas et une analyse bibliographique}

HISTORIQUE : La sténose des veines pulmonaires est une cause rare d'hypertension pulmonaire, à l'apparition et à la présentation variables. Au moins l'une des quatre veines pulmonaires peut faire l'objet d'une atteinte primaire ou secondaire. Une fillette de cinq mois a consulté en raison d'une détresse respiratoire, d'une léthargie et d'une cyanose exigeant une intubation.

MÉTHODOLOGIE : Léchocardiographie a révélé une dilatation ventriculaire droite, une pression systolique ventriculaire droite de $97 \mathrm{mmHg}$, une fraction d'éjection réduite et un débit turbulent à l'oreillette droite. Le cathétérisme cardiaque a signalé une sténose des veines pulmonaires gauches, pour laquelle la patiente a subi une intervention de Coles.

RÉSULTATS : Après l'opération, on a constaté une amélioration transitoire de l'hypertension de la patiente, dont l'état s'est ensuite détérioré. Son pronostic était considéré comme peu réjouissant, et il a été entendu avec la famille de suspendre les soins.

CONCLUSION : La sténose des veines pulmonaires est une cause rare d'hypertension pulmonaire et s'associe à une morbidité et une mortalité importantes. L'intervention chirurgicale peut être bénéfique dans certains cas. Il va sans dire que le traitement aura de meilleures chances de réussir s'il est administré avant que l'hypertension pulmonaire se soit fixée. Le diagnostic précoce dépend d'un fort indice de présomption clinique.

and a systolic blood pressure of $70 \mathrm{mmHg}$. She had stridor, moderate to severe indrawing and no digital clubbing. There was a right ventricular heave, a single, loud S2 and a grade 2/6 systolic murmur heard throughout the precordium. Her liver was palpable $3 \mathrm{~cm}$ below the right costal margin. The remainder of the physical examination was unremarkable.

The patient's venous blood $\mathrm{pH}$ was 7.34 , with partial pressure of carbon dioxide at $53 \mathrm{mmHg}$ and a white blood cell count of $15 \times 10^{9} / \mathrm{L}$. A chest radiograph revealed cardiomegaly with a large right atrium, prominent pulmonary vessels and bilateral interstitial thickening. Echocardiography ascertained a right ventricular systolic pressure of $97 \mathrm{mmHg}$, with a concurrent systolic blood pressure of $70 \mathrm{mmHg}$ measured in the right arm. There was moderate tricuspid regurgitation and a dilated right ventricle, with a severely reduced ejection fraction (Figure 1). The interventricular septum was bowed toward the left ventricle in systole and was flat in diastole. Turbulent flow at the orifice of the left atrium was also seen, suggestive of stenosis of the left lower pulmonary veins.

The patient was transferred to the intensive care unit, where bilevel positive airway pressure was initiated. Sildenafil was continued, nitric oxide at 20 parts per million was started

The Hospital for Sick Children, Toronto, Ontario

Correspondence: Dr Reshma Amin, 105 Latimer Avenue, Toronto, Ontario M5N 2M3. Telephone 416-488-2165, fax 416-813-6246,

e-mail reshma.amin@utoronto.ca,reshma.amin@sickkids.ca 


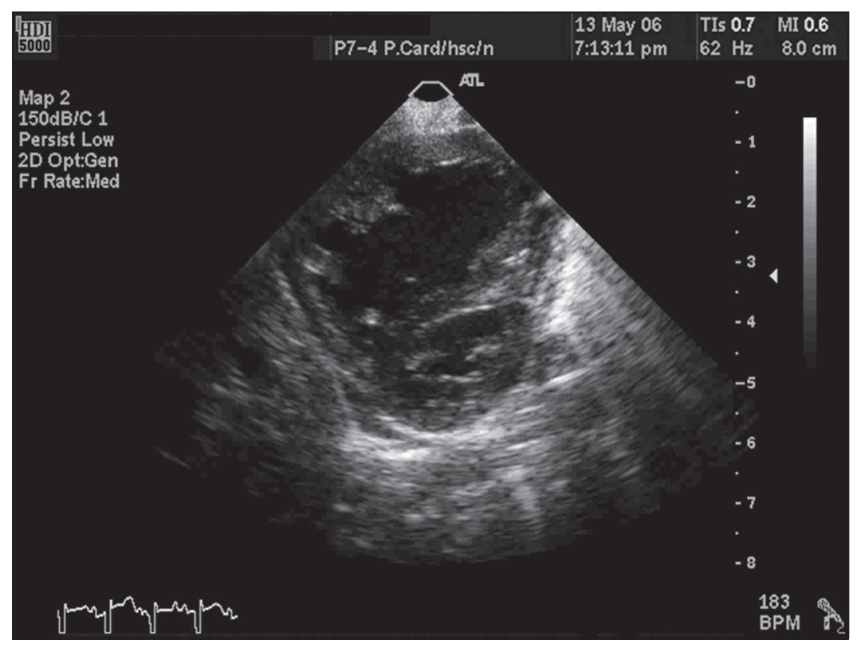

Figure 1) Echocardiogram showing a dilated right ventricle compressing the left ventricle and a bowed interventricular septum

and she was diuresed. After blood and nasopharygeal swab cultures were obtained, she was started on antibiotics empirically. However, she deteriorated $48 \mathrm{~h}$ later and was intubated because of poor oxygenation. She developed hemodynamic instability, which was managed with intravenous epinephrine, milrinone and dopamine.

A computed tomography (CT) scan of the chest showed enlargement of the right ventricle and main pulmonary artery, diffuse reticular markings of the lung parenchyma and a hypoplastic left pulmonary artery (Figure 2). Cardiac catheterization confirmed severe stenosis of the left-sided pulmonary veins at the junction of the left atrium, normal right pulmonary veins and an elevated pulmonary vascular resistance of 17 Wood units.

Open surgical repair in the form of a left-sided Coles procedure was performed. An intraoperative transesophageal echocardiogram demonstrated a right ventricular systolic pressure of $52 \mathrm{mmHg}$ (systolic blood pressure of $89 \mathrm{mmHg}$ measured concurrently in the right arm). The patient failed multiple attempts at extubation. She redeveloped suprasystemic pulmonary hypertension and was treated with sedation, muscle paralysis, nitric oxide, sildenafil, prostacyclin and diuresis. Despite this management, she developed worsening cardiac function with increasing compromise of the left ventricle. She failed to improve and a decision was made with the family to withdraw care.

\section{DISCUSSION}

Pulmonary vein stenosis (PVS) is a rare condition, with a reported prevalence of 1.7 per 100,000 children younger than two years of age (1). It is exceptionally difficult to manage, and is associated with less than a $50 \%$ survival rate within five years of diagnosis $(1,2)$. PVS has been reported in $0.5 \%$ of pediatric autopsy cases (3).

Historically, PVS has been considered to be a congenital abnormality, but primary PVS is the preferred terminology because the literature suggests that PVS is progressive and may not be present from birth (2). Primary PVS is believed to result from the abnormal incorporation of the common pulmonary vein into the left atrium in the later stages of cardiac development (4). However, recent evidence (2) suggests that PVS can also be secondary, and may develop as a result of cardiopulmonary surgery or catheter intervention. Approximately one-half of pediatric patients with primary PVS have an associated cardiac defect (2). Similar to the present case, primary PVS has also been associated with BPD and preterm birth $(2,4)$. It has been hypothesized that many of the factors that predispose patients to BPD may, in fact, also contribute to the development of PVS in the preterm infant (1). In pediatrics, secondary PVS occurs most commonly after surgical treatment for total anomalous pulmonary venous drainage (2). Clinically significant PVS occurs in $10 \%$ of postoperative total anomalous pulmonary venous drainage patients $(5,6)$.

The pathophysiology of PVS is helpful in understanding the clinical presentation. There is a diverse spectrum of disease. The stenosis usually occurs at the anastomosis between the left atrium and the pulmonary vein confluence, or may extend into the individual pulmonary veins (1). A left-sided PVS causes increased back pressure proximal to the stenosis, decreasing left pulmonary artery flow and increasing right pulmonary artery flow. Ventilation and perfusion mismatch results, with decreased gas exchange in the left lung (7). Over time, the left pulmonary artery becomes hypoplastic because of longstanding decreased blood flow. As a result, these patients are more sensitive to pulmonary stresses such as infection.

Our patient had unilateral PVS but with radiographic evidence of bilateral reticular markings consistent with pulmonary edema. As a consequence of left-sided PVS, hydrostatic pressure was elevated secondary to pulmonary venous hypertension and left-sided pulmonary edema developed as per Starling's forces. However, bilateral pulmonary edema explained the patient's acute deterioration. The pulmonary hypertension crisis at the time of presentation led to hypoxemia that triggered an increase in pulmonary vascular resistance, increased hydrostatic pressure and worsened pulmonary edema. Given the extent of the baseline pulmonary hypertension in our patient, pulmonary vascular recruitment was likely limited, which explained the inability of the pulmonary circulation to accommodate an acute increase in pulmonary pressures. The latter, in combination with the underlying $\mathrm{BPD}$, may account for the patient's cardiorespiratory failure despite unilateral disease.

PVS typically presents in the first few years of life. There is debate as to whether the number of pulmonary veins involved and the degree of obstruction affects the onset and severity of presentation $(2,8)$. Symptoms of pulmonary hypertension are not typical at early presentation - patients often present with tachypnea and recurrent pneumonia instead (2). As the disease progresses and pulmonary hypertension becomes more prominent, patients may develop a new murmur, right ventricular heart failure and pulmonary edema, failure to thrive or hemoptysis $(1,2,7)$.

Noninvasive tests such as echocardiography with Doppler ultrasound, magnetic resonance imaging, multidetector CT angiography and radionuclide quantitative pulmonary flow imaging may detect PVS $(2,9)$. The finding of turbulent flow on echocardiography with Doppler ultrasound should raise the suspicion of PVS (2). Because patients with PVS often have cardiac anomalies, pulmonary hypertension may mistakenly be attributed to the cardiac findings instead of the underlying 

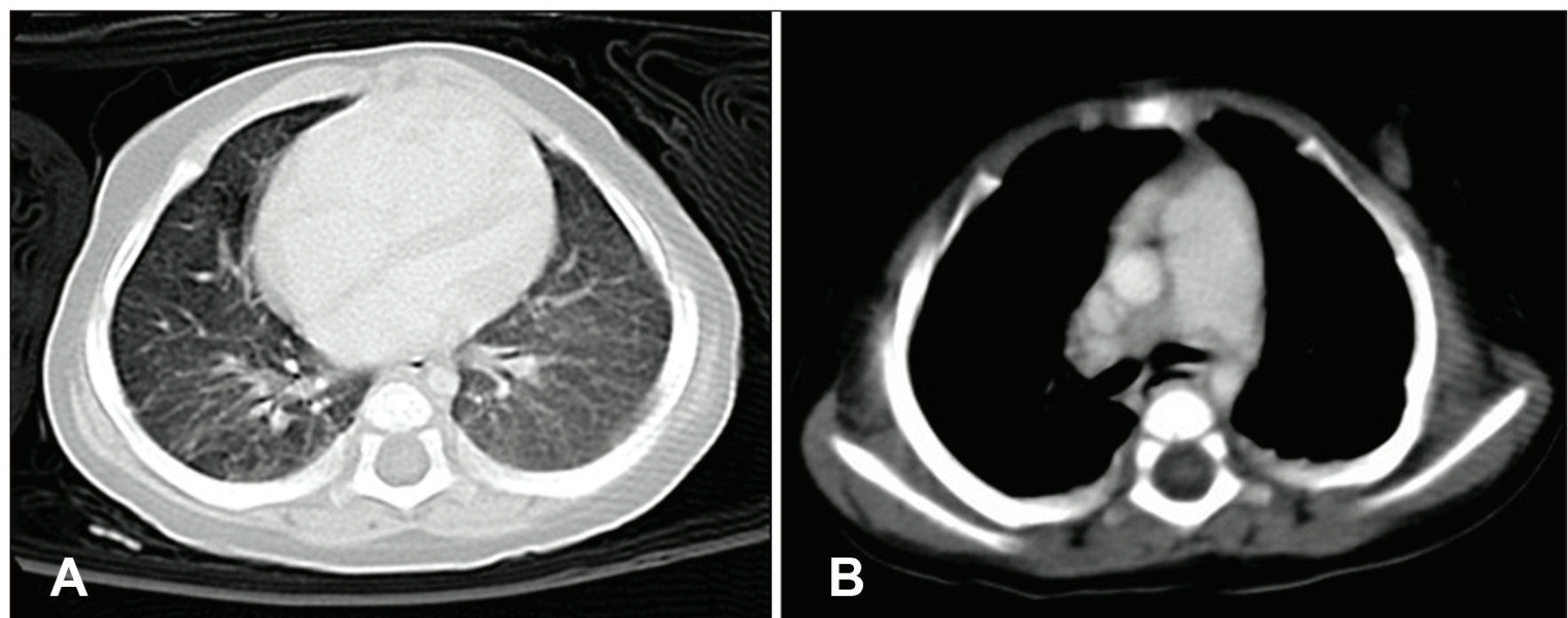

Figure 2) Computed tomography scan of the chest performed after the patient deteriorated. A Increased bilateral reticular markings in the lung fields. B Enlarged pulmonary artery

PVS $(2,9)$. In addition to the right ventricular failure in the present case, our patient also had mild BPD that was out of proportion to the degree of pulmonary hypertension. Visualization of all four pulmonary veins in patients with unexplained pulmonary hypertension or cardiac abnormalities on echocardiography is recommended. Magnetic resonance imaging and CT angiography are also useful noninvasive diagnostic tools for PVS. Both are able to provide three-dimensional views of the pulmonary veins but are limited by spatial resolution (2). Given the ventilation-perfusion mismatch that develops in the context of one-sided PVS, radionuclide quantitative pulmonary flow imaging is an excellent tool to evaluate the distribution of pulmonary blood flow. This tool is useful to evaluate patients preoperatively and to follow them over time (2).

There are reports of missing PVS when using noninvasive diagnostic techniques alone (1). Therefore, cardiac catheterization (or angiography) remains the gold standard for the diagnosis of PVS. A catheter is advanced into the pulmonary arteries, and segments that drain each of the pulmonary veins are identified; if PVS is present, flow will be reduced or absent (2).

The management of PVS is surgical and, presently, the Coles procedure (a 'sutureless' technique) is the preferred surgical repair method $(1,2,10)$. An incision is made in the left atrium and along the entire length of the pulmonary vein confluence, which can be continued into the individual pulmonary veins if needed $(5,11)$. The left atrial wall is then attached to the pericardium in a circle around the pulmonary veins, avoiding stitches in the cut edges of the pulmonary veins (5). The purpose of this approach is to reduce trauma to the pulmonary veins by reducing any stimulus for the regrowth of obstructive tissue (2). Unfortunately, the five-year survival and reoperation-free rate is only $50 \%(10,12)$. Other surgical interventions include balloon dilation and stent insertion (2). Some authors have argued for a role for balloon dilation in the management of resistant PVS lesions (13). Stent insertion has fallen out of favour, given the almost 100\% restenosis rate $(14,15)$. Pneumonectomy may be needed for refractory hemoptysis; lung transplantation has rarely been performed for severe pulmonary hypertension (2).
The prognosis for primary and secondary PVS remains guarded. If PVS is left untreated, and most or all of the pulmonary veins are affected, the condition is almost uniformly fatal; death is usually secondary to a pulmonary hypertension crisis, pulmonary or intercurrent infection, or hemoptysis (2). As a result of the raised awareness of PVS, more cases of milder forms are being diagnosed in relatively asymptomatic patients (2). Given that Holt et al (8) reported initial mean pulmonary arterial pressure to be an independent predictor of lung death in PVS patients, early diagnosis may lead to improved survival for these individuals. The authors also reported that patients presenting in infancy should be considered at high risk for mortality, regardless of the number of veins involved (8). Therefore, our patient had a significantly elevated risk of mortality given her young age at presentation and suprasystemic pulmonary pressures.

\section{SUMMARY}

PVS is a rare cause of pulmonary hypertension, and is associated with significant morbidity and mortality. Once the diagnosis is made, management is primarily surgical, with only a $50 \%$ success rate. It stands to reason that any treatment will have the best chance of success if completed before pulmonary hypertension becomes fixed. Early diagnosis depends on a high index of clinical suspicion.

\section{REFERENCES}

1. Drossner DM, Kim DW, Maher KO, Mahle WT. Pulmonary vein stenosis: Prematurity and associated conditions. Pediatrics 2008;122:e656-61.

2. Latson LA, Prieto LR. Congenital and acquired pulmonary vein stenosis. Circulation 2007;115:103-8.

3. Howels-Gurich H. Pulmonary vein stenosis. Orphanet Encyclopedia March 2003

4. Edwards JE. Congenital stenosis of pulmonary veins: Pathologic and developmental considerations. Lab Invest 1960;9:46-66.

5. Calderone C, Najm H, Kadletz, M, Smallhorn J, Freedom R. Relentless pulmonary vein stenosis after repair of total anomalous pulmonary venous drainage. Ann Thorac Surg 1998;66:1514-20.

6. Hancock Friesen CL, Zurakowski D, Thiagarajan RR, et al. Total anomalous pulmonary venous connection: An analysis of current management strategies in a single institution. Ann Thorac Surg 2005;79:596-606 
7. Holcomb R, Tyson RW, Dunbar Ivy D, Abman S, Kinsella J. Congenital pulmonary venous stenosis presenting as persisitent pulmonary hypertension of the newborn. Pediatr Pulmonol 1999;28:301-6.

8. Holt DB, Moller JH, Larson S, Johnson MC. Primary pulmonary vein stenosis. Am J Cardiol 2007;99:568-72.

9. Breinholt JP, Hawkins JA, Minich L, et al. Pulmonary vein stenosis with normal connection: Associated cardiac abnormalities and variable outcome. Ann Thorac Surg 1999;68:164-8.

10. Devaney EJ, Chang AC, Ohye RG, Bove EL. Management of congenital and acquired pulmonary vein stenosis. Ann Thorac Surg 2006;81:992-6.

11. The Cardiothoracic Surgery Network. 'Sutureless' pulmonary vein stenosis repair. <http://www.ctsnet.org/sections/clinicalresources/ congenital/expert_tech-3.html> (Version current at April 17, 2009).
12. Yun TJ, Coles JG, Konstantinov IE, et al. Conventional and sutureless techniques for management of the pulmonary veins: Evolution of indications from post-repair pulmonary vein stenosis to primary pulmonary vein anomalies. J Thorac Surg 2005; 129:167-74.

13. Seale AN, Daubenay PE, Magee AG, et al. Pulmonary vein stenosis: Initial experience with cutting balloon angioplasty. Heart 2006;92:815-20.

14. Tomita H, Watanabe K, Yazaki S, et al. Stent implantation and subsequent dilatation for pulmonary vein stenosis in pediatric patients: Maximizing effectiveness. Circulation 2003;67:187-90.

15. Mendelsohn AM, Bove EL, Lupinetti FM, et al. Intraoperative and percutaneous stenting of congenital pulmonary artery and vein stenosis. Circulation 1993;88:210-7. 


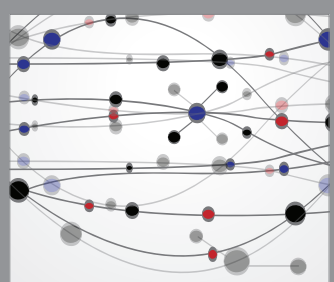

The Scientific World Journal
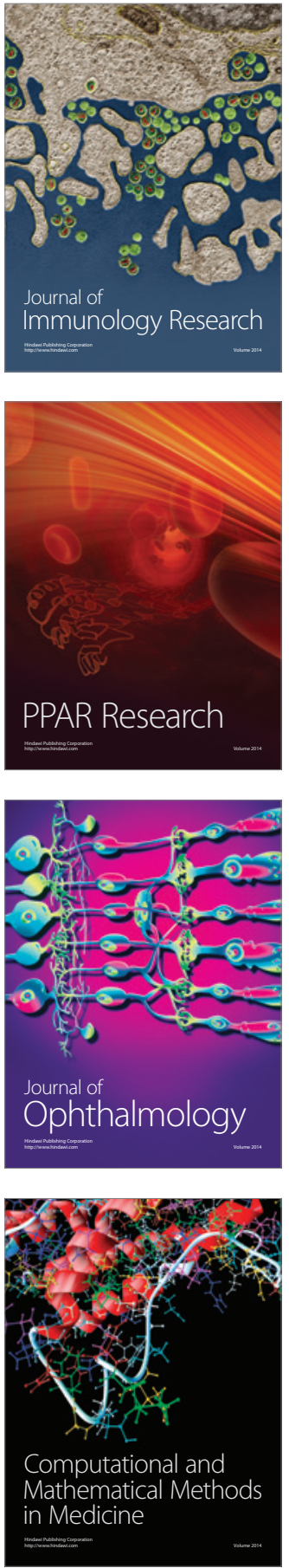

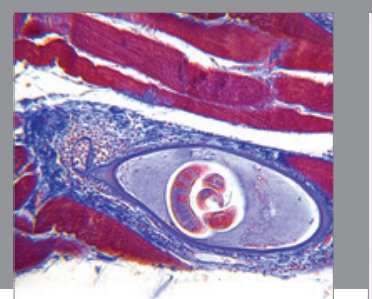

Gastroenterology Research and Practice

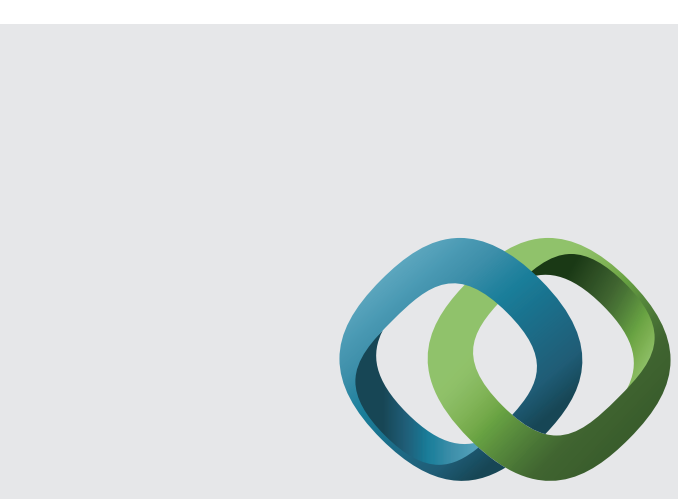

\section{Hindawi}

Submit your manuscripts at

http://www.hindawi.com
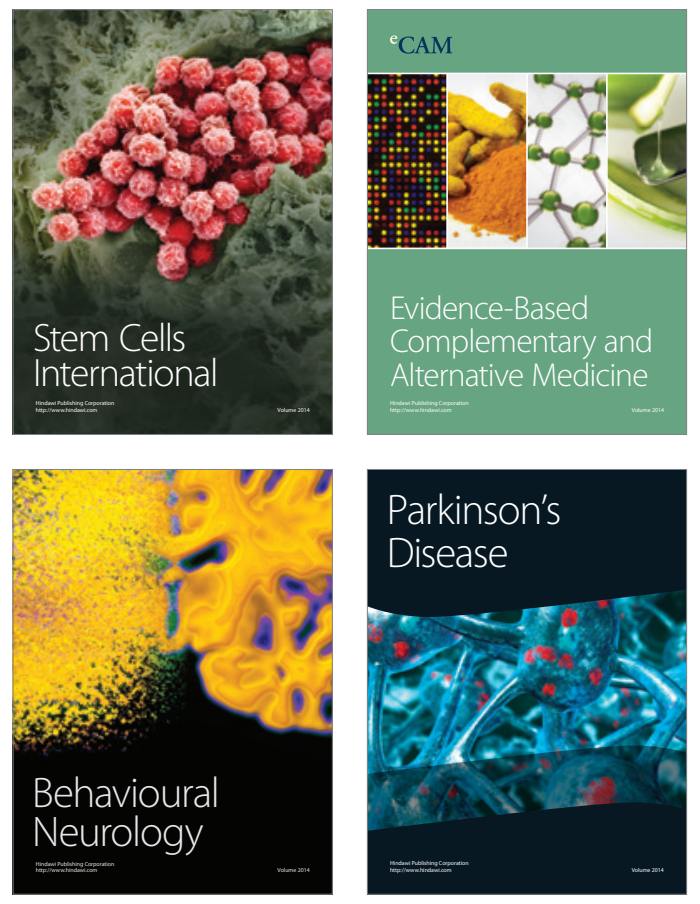
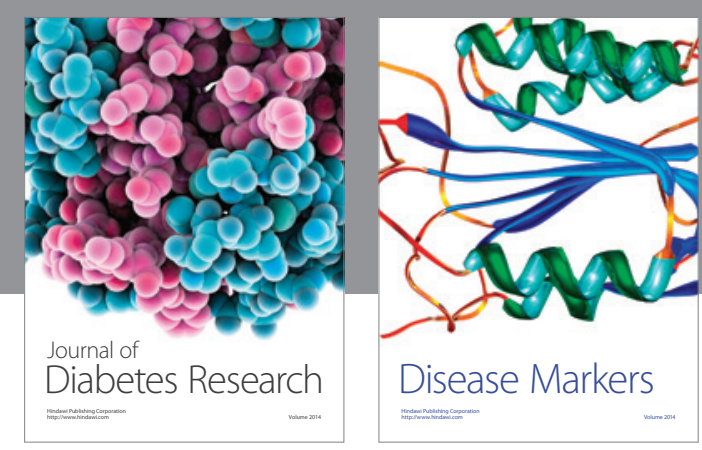

Disease Markers
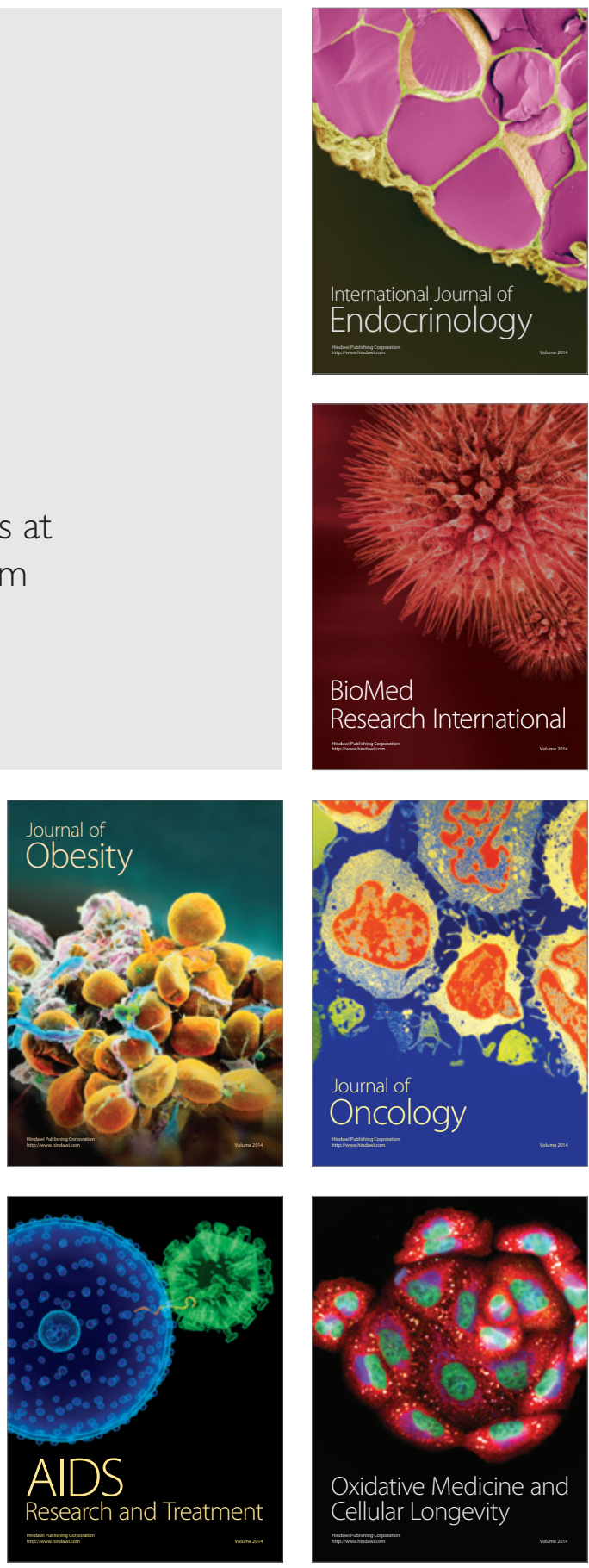